\title{
BMJ Open Healthcare utilisation by pregnant patients with asthma in South Korea: a cohort study using nationwide claims data
}

Chang-Hoon Lee, ${ }^{1,2}$ Jimin Kim, ${ }^{1}$ Eun Jin Jang, ${ }^{1,3}$ Yun Jung Kim, ${ }^{1}$ Seongmi Choi, ${ }^{1,4}$ Joon-Ho Lee, ${ }^{5}$ Deog Kyeom Kim, ${ }^{1,6}$ Jae-Joon Yim, ${ }^{1,2}$ Ho II Yoon ${ }^{1,7}$

To cite: Lee C-H, Kim J, Jang EJ, et al. Healthcare utilisation by pregnant patients with asthma in South Korea: a cohort study using nationwide claims data. $B M J$ Open 2015;5:e008416. doi:10.1136/bmjopen-2015008416

- Prepublication history for this paper is available online. To view these files please visit the journal online (http://dx.doi.org/10.1136/ bmjopen-2015-008416).

Received 9 April 2015 Revised 18 August 2015 Accepted 8 October 2015

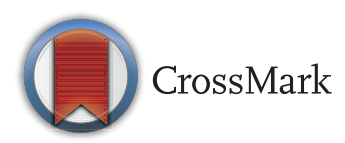

For numbered affiliations see end of article.

Correspondence to Professor Ho II Yoon; dextro@snu.ac.kr

\section{ABSTRACT}

Objectives: Few nationwide population-based studies have examined the burden of asthma during pregnancy. Here, we investigated the burden and medical treatment of asthma during pregnancy requiring healthcare utilisation in South Korea.

Design: Cohort study.

Setting: Nationwide insurance claims database. Participants: A total of 1306281 pregnant women who delivered in South Korea in 2009-2011.

Outcomes: The prevalence and exacerbation rates of asthma requiring healthcare utilisation, and the prescription of antiasthmatic drugs during pregnancy.

Results: The prevalence of asthma requiring healthcare utilisation was $0.43 \%$ among pregnant women. Among those with asthma requiring healthcare utilisation, $6.9 \%$ were hospitalised and treated with systemic steroids and short-acting $\beta_{2}$-agonists during pregnancy. Oral drugs were prescribed less during the third trimester than during the first trimester (all $p$ values for trends were $<0.001$ ). A significant number of patients with asthma were likely to stop taking antiasthmatic drugs after becoming pregnant.

Conclusions: The prevalence of asthma requiring healthcare utilisation during pregnancy was not very high. However, a significant number of women were likely to stop taking antiasthmatic drugs, and those who did tended to experience exacerbations.

\section{INTRODUCTION}

Asthma is an important health condition during pregnancy. Approximately 8\% of pregnant women in the USA currently have asthma, and $4.1 \%$ of them experience at least one asthma attack. ${ }^{1}$ One prospective study also reported that the majority of pregnant women who seek respiratory specialist care for dyspnoea are asthmatics or probable asthmatics. ${ }^{2}$ Asthma seems to increase the risk of low birth weight, pre-eclampsia, ${ }^{3}$ preterm delivery and congenital malformations. ${ }^{4}$ Patients with asthma are also

\section{Strengths and limitations of this study}

- A study analysing asthma requiring healthcare utilisation during pregnancy using a large-scale nationwide database.

- The diagnosis of asthma was defined as its International Classification of Diseases 10th Edition code together with the patient's use of antiasthmatic medication.

- The results showed that a significant number of patients were likely to stop taking drugs after becoming pregnant and that the prescription of oral drugs decreased during pregnancy.

- Although only a portion of the asthmatic pregnant women required healthcare utilisation, our results showed a real-world healthcare utilisation pattern of asthmatics during pregnancy.

susceptible to drug safety issues. For example, treatment with systemic corticosteroids during asthma could increase the risk of pre-eclampsia, low birth weight and preterm delivery. ${ }^{5}$ Although several studies have reported that inhaled corticosteroids (ICSs) and $\beta$-agonists did not affect pregnancy outcomes, ${ }^{5-8}$ many women commonly avoid taking asthma drugs during pregnancy because of these safety issues. ${ }^{9} 10$

However, few nationwide population-based studies have been performed of the actual burden and treatment of asthma during pregnancy. ${ }^{1}$ The national insurance programme of South Korea covers more than $95 \%$ of Koreans. Although the prevalence of asthma among people aged 20-39 years is reportedly $0.5-2 \%,{ }^{11}{ }^{12}$ that of asthma among pregnant women has never been investigated. In this study, we investigated the prevalence of asthma requiring healthcare utilisation during pregnancy in South Korea, incidence of severe asthma exacerbations and actual medical treatment of these patients using a nationwide insurance claims database. 


\section{METHODS}

\section{Data source}

The Health Insurance Review and Assessment Service (HIRA, Seoul, Republic of Korea) is a governmental agency that examines the accuracy of claims submitted to the National Health Insurance (NHI) and National Medical Aid (NMA) in South Korea, which covers approximately $96.6 \%$ of the entire 48.6 million South Korean population. We used the HIRA database, which includes information regarding demographic variables and all of the rendered medical services along with diagnostic codes (International Statistical Classification of Diseases and Related Health Problems, 10th Edition code, ICD-10), and all of the dispensed prescribed medications. The proportion of missing or out-of-range answers in terms of key fields, including drug names, quantity, date dispensed and duration, comprised $<0.5 \%$ of the records. ${ }^{13}$ Written informed consent was not required due to the study's retrospective nature. Patient records and information were anonymised and de-identified prior to the analysis.

\section{Analyses}

We identified a pregnancy whenever a claim about a delivery event was found. The initiation pregnancy date was calculated as the date 40 weeks before the delivery event. If a woman was pregnant more than once, only the first pregnancy was included in the analysis. In our study, we focused on patients with asthma who required healthcare utilisation (who visited hospitals and received a physician's diagnosis and care). To increase the diagnostic accuracy and reduce bias, asthma was defined in two ways: (1) definition 1: ICD-10 code J45 or $\mathrm{J} 46$ that was repeated with at least a 1 month interval; and (2) definition 2: definition 1 plus use of any asthma medication at least once. Asthma medication included ICSs, ICS combined with inhaled long-acting $\beta$-agonists (ICS/LABAs), inhaled short-acting $\beta$-agonists (SABAs), leukotriene receptor antagonists (LTRAs) and theophylline.

The prevalence of asthma requiring healthcare utilisation during pregnancy was calculated as the number of asthma cases per 100 pregnancies (\%). We also estimated the incidence rates of severe exacerbations of asthma (number of cases per pregnancy). We defined severe exacerbations in two ways: (1) a visit to the emergency room or hospitalisation with a diagnosis of asthma and (2) condition 1 plus treatment with systemic corticosteroids or SABAs. Asthma medications prescribed within 14 weeks before the initiation date of pregnancy and those prescribed during each pregnancy trimester were also evaluated. We evaluated whether there were significant trends across trimesters in the use of medications using Mantel-Haenszel statistics. ${ }^{14}$ All analyses were performed using SAS 9.2 software (SAS Institute, Cary, North Carolina, USA) and Stata V.13.1 software (StataCorp, College Station, Texas, USA).

\section{RESULTS}

A total of 1306281 pregnant women (mean age, 30.62 \pm 4.49 years) were observed in 2009-2011. Of them, 5589 were diagnosed with asthma (definition 1 prevalence of 0.43\% in 2009-2010: $0.44 \%$ in 2009, $0.41 \%$ in 2010). Among them, 3825 were prescribed asthma drugs at least once during pregnancy (definition 2 prevalence of 0.29\% in 2009-2010: $0.29 \%$ in 2009 and $0.28 \%$ in 2010). Table 1 shows how many pregnant women with asthma experienced exacerbations. Among the total number of pregnant women with asthma requiring healthcare utilisation, $11.6 \%$ visited the emergency department or were admitted to the hospital for asthma treatment (incidence, 0.17 per pregnancy) and $6.9 \%$ were treated with systemic steroids and SABA after visiting the emergency department or hospitalised for asthma treatment (incidence, 0.09 per pregnancy). Among the pregnant women with asthma who were treated with asthma medications, $16 \%$ visited the emergency department or were hospitalised for asthma treatment (incidence, 0.23 per pregnancy) and $10 \%$ were treated with systemic steroids and SABA after visiting the emergency department or being hospitalised for asthma treatment (incidence, 0.13 per pregnancy).

More than half of the pregnant women with asthma were prescribed either ICS/LABA $(27.9 \%)$ or ICS alone $(25.2 \%)$. The most commonly prescribed ICS/LABA was fluticasone/salmeterol (19.2\%), while the most commonly used ICS was budesonide $(22.1 \%)$. LTRA, theophylline and systemic steroids were used in 29\%, 9.2\% and $9.1 \%$ of cases, respectively. These oral drugs were less prescribed during the third trimester than during the first trimester (all $\mathrm{p}$ values for trends were $<0.001$; table 2).

To evaluate how patients with asthma changed their treatment compliance after pregnancy, we also analysed 82710 patients from the overall cohort who were diagnosed with asthma (ICD-10 code J45-J46 on at least one occasion) within 2 years before pregnancy. Compared with the period within 14 weeks just before pregnancy, the date of asthma medication use during pregnancy was markedly decreased (table 3 ).

\section{DISCUSSION}

This study showed a prevalence of asthma requiring healthcare utilisation during pregnancy of $0.43 \%$ in South Korea. In a field survey conducted more than 10 years ago of a randomly recruited general population from cities and rural areas in Korea, the prevalence of current asthma, defined as current wheezing and positive bronchial hyper-responsiveness, in participants aged $\leq 39$ years was approximately $2 \% .{ }^{12}$ Considering that only a small percentage of patients seek healthcare services, the prevalence in our study may be reasonable. The prevalence of asthma during pregnancy was comparable to or slightly lower than that in the previous report in which, on the basis of the insurance database, 
Table 1 The incidence of emergency room visits or hospitalisation for asthma exacerbations during pregnancy

\begin{tabular}{lll}
$\begin{array}{l}\text { Number of patients } \\
\text { with events }(\%)\end{array}$ & $\begin{array}{l}\text { Number of } \\
\text { events }\end{array}$ & $\begin{array}{l}\text { Incidence } \\
\text { (per pregnancy) }\end{array}$ \\
\hline
\end{tabular}

Definition 1: Among all pregnant women with asthma

In the complete study period ( $\mathrm{n}=5589 ; 0.43 \%$ among all pregnant women)

$\begin{array}{llll}\text { (1) ER visit or hospitalisation for asthma treatment } & 647(11.6 \%) & 926 & 0.17\end{array}$

(2) Condition 1+treatment with systemic steroids or SABA $383(6.9 \%) \quad 506 \quad 0.09$

In 2009 ( $n=1986 ; 0.44 \%$ of all pregnant women)

(1) ER visit or hospitalisation due to asthma

(2) Condition 1+treatment with systemic steroids or SABA

In 2010 ( $n=1864 ; 0.41 \%$ of all pregnant women)

(1) ER visit or hospitalisation for asthma treatment

$223(11.2 \%)$

324

0.16

$127(6.4 \%)$

170

0.09

(2) Condition 1+treatment with systemic steroids or SABA

$213(11.4 \%)$

318

0.16

Definition 2: Definition 1 and treatment with antiasthmatic drugs

In the complete study period ( $n=3825 ; 0.29 \%$ of all pregnant women)
(1) ER visit or hospitalisation due to asthma
$613(16 \%)$
(2) Condition 1+treatment with systemic steroids or SABA
$383(10 \%)$
886
0.23
In 2009 ( $n=1325 ; 0.29 \%$ of all pregnant women)
(1) ER visit or hospitalisation for asthma treatment
$213(16.1 \%)$
506
0.13
(2) Condition 1+treatment with systemic steroids or SABA
$127(9.6 \%)$
313
0.24
In 2010 ( $n=1274 ; 0.28 \%$ of all pregnant women)
(1) ER visit or hospitalisation due to asthma
$201(15.8 \%)$
170
0.13
(2) Condition 1+treatment with systemic steroids or SABA
$132(10.4 \%)$
305
0.23

184

0.09

ER, emergency room; SABA, short-acting $\beta 2$-agonists.

the prevalence of asthma in the Korean general population aged $20-39$ years was reportedly $4.65-6.73$ cases per 1000 persons. $^{11}$

Significant numbers of pregnant women with asthma experienced severe exacerbations in our study. Among the women who were diagnosed with asthma, $11.6 \%$ visited the emergency room or were admitted to a hospital for asthma treatment, while $6.9 \%$ were also treated with systemic steroids and SABA, findings that are consistent with the results of previous studies. ${ }^{15-18}$ This finding could be associated with the general low rate of asthma medication use during pregnancy. Among the 82710 patients with suspected asthma who were diagnosed with asthma within 2 years before pregnancy, only $4.9 \%$ were prescribed asthma drugs at least once. The most common drugs prescribed for asthma during

Table 2 Asthma treatment among pregnant women with asthma $(n=5589)$

\begin{tabular}{|c|c|c|c|c|c|c|c|c|c|}
\hline & \multicolumn{2}{|l|}{ Total } & \multicolumn{2}{|c|}{ 1st trimester } & \multicolumn{2}{|c|}{ 2nd trimester } & \multicolumn{2}{|c|}{ 3rd trimester } & \multirow[b]{2}{*}{ P for trend } \\
\hline & $\mathrm{n}$ & $(\%)$ & $\mathrm{n}$ & $(\%)$ & $\mathrm{n}$ & (\%) & $\bar{n}$ & (\%) & \\
\hline ICS or LABA & & & & & & & & & 0.678 \\
\hline Neither ICS nor LABA & 2581 & $(46.2)$ & 4084 & (73.1) & 3968 & (71) & 4060 & (72.6) & \\
\hline LABA only & 41 & $(0.7)$ & 17 & $(0.3)$ & 16 & $(0.3)$ & 14 & $(0.3)$ & \\
\hline ICS without LABA & 1407 & (25.2) & 633 & (11.3) & 730 & (13.1) & 663 & (11.9) & \\
\hline ICS with LABA & 1560 & (27.9) & 855 & (15.3) & 875 & (15.7) & 852 & (15.2) & \\
\hline \multicolumn{10}{|l|}{ ICS/LABA } \\
\hline Fluticasone/salmeterol & 1071 & $(19.2)$ & 599 & $(10.7)$ & 574 & (10.3) & 550 & (9.8) & 0.127 \\
\hline Budesonide/formoterol & 569 & (10.2) & 272 & $(4.9 \%)$ & 319 & $(5.7 \%)$ & 314 & $(5.6 \%)$ & 0.079 \\
\hline \multicolumn{10}{|l|}{ ICS } \\
\hline Fluticasone & 74 & (1.3) & 30 & $(0.5)$ & 39 & $(0.7)$ & 41 & $(0.7)$ & 0.198 \\
\hline Budesonide & 1236 & (22.1) & 550 & (9.8) & 626 & (11.2) & 574 & (10.3) & 0.458 \\
\hline Other ICS & 115 & $(2.1)$ & 57 & (1) & 67 & $(1.2)$ & 55 & (1) & 0.854 \\
\hline \multicolumn{10}{|l|}{ LABA } \\
\hline Salmeterol & 40 & $(0.7)$ & 17 & $(0.3)$ & 16 & $(0.3)$ & 13 & $(0.2)$ & 0.470 \\
\hline Formoterol & 1 & $(0.0)$ & 0 & $(0.0)$ & 0 & $(0.0)$ & 1 & $(0.0)$ & 0.221 \\
\hline SABA & 1805 & (32.3) & 901 & (16.1) & 924 & (16.5) & 772 & (13.8) & 0.001 \\
\hline LTRA & 1620 & (29) & 1081 & (19.3) & 675 & (12.1) & 516 & $(9.2)$ & $<0.001$ \\
\hline Theophylline & 515 & (9.2) & 283 & (5.1) & 159 & (2.8) & 105 & (1.9) & $<0.001$ \\
\hline Systemic steroids & 509 & (9.1) & 301 & (5.4) & 214 & (3.8) & 201 & (3.6) & $<0.001$ \\
\hline
\end{tabular}


Table 3 Asthma medication before and after pregnancy among asthma suspects ( $n=82710$ )

\begin{tabular}{|c|c|c|c|c|c|c|c|c|c|c|c|c|}
\hline & \multicolumn{2}{|c|}{$\begin{array}{l}\text { Before } \\
\text { pregnancy }\end{array}$} & \multicolumn{8}{|c|}{ During pregnancy } & \multicolumn{2}{|l|}{ p Value } \\
\hline & \multirow[b]{2}{*}{$\mathbf{n}$} & \multirow[b]{2}{*}{$(\%)$} & \multicolumn{2}{|c|}{ total } & \multicolumn{2}{|c|}{ 1st trimester } & \multicolumn{2}{|c|}{ 2nd trimester } & \multicolumn{2}{|c|}{ 3rd trimester } & \multirow{2}{*}{$\begin{array}{l}\text { Before vs } \\
\text { during }\end{array}$} & \multirow{2}{*}{$\begin{array}{l}\text { Trend during } \\
\text { pregnancy }\end{array}$} \\
\hline & & & $\mathbf{n}$ & $(\%)$ & $\mathbf{n}$ & $(\%)$ & $\mathbf{n}$ & $(\%)$ & $\mathbf{n}$ & $(\%)$ & & \\
\hline None & 56695 & (68.6) & 78681 & (95.1) & 80101 & (96.9) & 81269 & (98.3) & 82534 & (99.8) & $<0.001$ & $<0.001$ \\
\hline ICS & 5250 & $(6.4)^{\prime}$ & 769 & $(0.9)$ & 389 & $(0.5)^{\prime}$ & 360 & $(0.4)$ & 328 & $(0.4)^{\prime}$ & $<0.001$ & 0.023 \\
\hline ICS+LABA & 2012 & $(2.4)$ & 801 & (1) & 416 & $(0.5)$ & 433 & $(0.5)$ & 438 & $(0.5)$ & $<0.001$ & 0.451 \\
\hline LTRA & 14932 & (18.1) & 1881 & (2.3) & 1484 & $(1.8)$ & 482 & $(0.6)$ & 257 & $(0.3)$ & $<0.001$ & $<0.001$ \\
\hline ICS+LTRA & 1708 & $(2.1)^{\prime}$ & 196 & $(0.2)$ & 108 & $(0.1)$ & 59 & $(0.1)$ & 46 & $(0.1)$ & $<0.001$ & $<0.001$ \\
\hline $\begin{array}{l}\text { ICS+LABA } \\
+ \text { LTRA }\end{array}$ & 2112 & (2.6) & 382 & $(0.5)$ & 212 & $(0.3)$ & 107 & $(0.1)$ & 107 & $(0.1)$ & $<0.001$ & $<0.001$ \\
\hline
\end{tabular}

pregnancy in South Korea were ICS or ICS/LABA, similar to those administered to non-pregnant patients with asthma. When ICS alone was used, budesonide was more commonly selected during pregnancy than fluticasone, although fluticasone/salmeterol was more widely chosen than budesonide/formoterol. This phenomenon might be influenced by the result of a subgroup analysis of a randomised controlled trial in which the safety of budesonide during pregnancy was demonstrated. ${ }^{7}$

The adherence rate with prescription drugs is relatively low, ${ }^{19}{ }^{20}$ and pregnant women with asthma are no exception. ${ }^{21} 22$ In our study, many women may have stopped taking antiasthmatic drugs after becoming pregnant, possibly due to concerns that they could affect pregnancy outcomes. In fact, the US Food and Drug Administration categorises the majority of asthma drugs including fluticasone, salmeterol, fluticasone/salmeterol, formoterol, budesonide/formoterol, salbutamol, theophylline and prednisolone into category C (risk not ruled out). However, it is widely accepted that it is safer for pregnant women with asthma to be treated with asthma medications than continuing to have asthma symptoms and exacerbations. ${ }^{23}$ Although no drug can be considered completely safe, ${ }^{10}$ the major antiasthmatic drugs are generally considered safe ${ }^{5-8}$ and uncontrolled asthma may be associated with poorer pregnancy outcomes. ${ }^{3} 418$ In fact, the guidelines state that poorly controlled asthma and exacerbations put babies at much greater risk than do current asthma treatments. ${ }^{24}$ In our study, a significant number of women were likely to stop antiasthmatic drugs and a substantial number of pregnant women with asthma did experience exacerbations, which might indirectly support the guidelines' emphasis on the adherence for asthma treatment during pregnancy.

The limitations of our study include that only a portion of our pregnant cohort had asthma requiring healthcare utilisation. Since this study was based on a claims database and not a survey, some pregnant women with mild or well-controlled asthma who did not need to seek medical attention may not have been included in the analysis. It is well known that similar percentages of women have improved, unchanged and worsened asthmatic symptoms during pregnancy. ${ }^{25}$ In addition, pregnant women who were not covered by NHI or NMA were not included in this study. Moreover, our data should be cautiously interpreted. First, the analyses of asthma treatment adherence and severe asthma exacerbation used different cohorts. Second, we cannot differentiate between physician prescribing behaviours and patient adherence. Therefore, as mentioned above, the association between poor asthma treatment adherence and the significant number of severe exacerbations during pregnancy cannot be considered a causal relationship.

In conclusion, in this analysis of a nationwide insurance claims database, the prevalence of asthma requiring healthcare utilisation during pregnancy was not very high. However, a significant number of women were likely to stop antiasthmatic drugs and experienced exacerbations. Careful management and further studies are needed to increase asthma treatment adherence during pregnancy.

\section{Author affiliations}

${ }^{1}$ Division for Healthcare Technology Assessment Research, National Evidencebased Healthcare Collaborating Agency, Seoul, Republic of Korea, Seoul, Republic of Korea

${ }^{2}$ Division of Pulmonary and Critical Care Medicine, Department of Internal Medicine, Seoul National University College of Medicine, Seoul National University Hospital, Seoul, Republic of Korea

${ }^{3}$ Department of Information Statistics, College of Natural Science, Andong National University, Andong, Republic of Korea

${ }^{4}$ Real Estate R\&D Institute, Korea Appraisal Board, Daegu, Republic of Korea ${ }^{5}$ Department of Obstetrics and Gynecology, Seoul National University College of College of Medicine, Seoul National University Hospital, Seoul, Republic of Korea

${ }^{6}$ Division of Pulmonary and Critical Care Medicine, Department of Internal Medicine, Seoul National University College of College of Medicine, Seoul Metropolitan Government-Seoul National University Boramae Medical Center, Seoul, Republic of Korea

${ }^{7}$ Division of Pulmonary and Critical Care Medicine, Department of Internal Medicine, Seoul National University College of Medicine, Seoul National University Bundang Hospital, Seongnam-Si, Republic of Korea

Acknowledgements The authors acknowledge Editage (https://www.editage. com) who provided English editing.

Contributors C-HL, JK and J-HL wrote the manuscript. JK, YJK, EJJ and SC analyzed the data. DKK and J-JY participated in the study design. C-HL and HIY planned the study. 
Funding This study was supported by the National Evidence-Based Healthcare Collaborating Agency (NA13-004), which contributed to the study's design, conduct and reporting.

Competing interests None declared.

Ethics approval This study was approved by the ethics review committee of the National Evidence-based Healthcare Collaborating Agency, Seoul, Republic of Korea.

Provenance and peer review Not commissioned; externally peer reviewed.

Data sharing statement No additional data are available.

Open Access This is an Open Access article distributed in accordance with the Creative Commons Attribution Non Commercial (CC BY-NC 4.0) license, which permits others to distribute, remix, adapt, build upon this work noncommercially, and license their derivative works on different terms, provided the original work is properly cited and the use is non-commercial. See: http:// creativecommons.org/licenses/by-nc/4.0/

\section{REFERENCES}

1. Kwon HL, Triche EW, Belanger K, et al. The epidemiology of asthma during pregnancy: prevalence, diagnosis, and symptoms. Immuno Allergy Clin North Am 2006;26:29-62.

2. Bidad K, Heidarnazhad H, Pourpak Z, et al. Frequency of asthma as the cause of dyspnea in pregnancy. Int $J$ Gynaecol Obstet 2010;111:140-3.

3. Murphy VE, Namazy JA, Powell $\mathrm{H}$, et al. A meta-analysis of adverse perinatal outcomes in women with asthma. BJOG 2011;118:1314-23.

4. Murphy VE, Wang G, Namazy JA, et al. The risk of congenital malformations, perinatal mortality and neonatal hospitalisation among pregnant women with asthma: a systematic review and meta-analysis. BJOG 2013;120:812-22.

5. Schatz M, Dombrowski MP, Wise R, et al. The relationship of asthma medication use to perinatal outcomes. J Allergy Clin Immunol 2004;113:1040-5.

6. Pauwels RA, Pedersen S, Busse WW, et al. Early intervention with budesonide in mild persistent asthma: a randomised, double-blind trial. Lancet 2003;361:1071-6.

7. Silverman M, Sheffer A, Diaz PV, et al. Outcome of pregnancy in a randomized controlled study of patients with asthma exposed to budesonide. Ann Allergy Asthma Immunol 2005;95:566-70.

8. Tata LJ, Lewis SA, McKeever TM, et al. Effect of maternal asthma exacerbations and asthma medication use on congenital malformations in offspring: a UK population-based study. Thorax 2008:63:981-7.

9. Malm H, Martikainen J, Klaukka T, et al. Prescription of hazardous drugs during pregnancy. Drug Saf 2004;27:899-908.

10. Vlastarakos PV, Manolopoulos L, Ferekidis E, et al. Treating common problems of the nose and throat in pregnancy: what is safe? Eur Arch Otorhinolaryngol 2008:265:499-508.

11. Park HS, Choi GS, Cho JS, et al. Epidemiology and current status of allergic rhinitis, asthma, and associated allergic diseases in Korea: ARIA Asia-Pacific workshop report. Asian Pac J Allergy Immunol 2009;27:167-71.

12. Kim YK, Kim SH, Tak YJ, et al. High prevalence of current asthma and active smoking effect among the elderly. Clin Exp Allergy 2002;32:1706-12.

13. Lee $\mathrm{CH}, \mathrm{Kim} \mathrm{K}$, Hyun MK, et al. Use of inhaled corticosteroids and the risk of tuberculosis. Thorax 2013;68:1105-13.

14. Agresti A. An Introduction to categorical data analysis: Wiley, 2007.

15. Schatz M, Dombrowski MP, Wise R, et al. Asthma morbidity during pregnancy can be predicted by severity classification. J Allergy Clin Immunol 2003;112:283-8.

16. Stenius-Aarniala BS, Hedman J, Teramo KA. Acute asthma during pregnancy. Thorax 1996;51:411-14.

17. Firoozi $\mathrm{F}$, Ducharme $\mathrm{FM}$, Lemière $\mathrm{C}$, et al. Effect of fetal gender on maternal asthma exacerbations in pregnant asthmatic women. Respir Med 2009;103:144-51.

18. Bakhireva LN, Schatz M, Jones KL, et al. Asthma control during pregnancy and the risk of preterm delivery or impaired fetal growth. Ann Allergy Asthma Immunol 2008;101:137-43.

19. Olesen C, Søndergaard C, Thrane N, et al. Do pregnant women report use of dispensed medications?. Epidemiology 2001;12:497-501.

20. Sawicki E, Stewart K, Wong S, et al. Medication use for chronic health conditions by pregnant women attending an Australian maternity hospital. Aust N Z J Obstet Gynaecol 2011:51:333-8.

21. Chambers K. Asthma education and outcomes for women of childbearing age. Case Manager 2003;14:58-61.

22. Murphy VE, Gibson PG, Talbot PI, et al. Asthma self-management skills and the use of asthma education during pregnancy. Eur Respir J 2005;26:435-41.

23. Dombrowski MP, Schatz M, ACOG Committee on Practice Bulletins-Obstetrics. ACOG practice bulletin: clinical management guidelines for obstetrician-gynecologists number 90, February 2008: asthma in pregnancy. Obstet Gynecol 2008;111:457-64.

24. Global Initiative for Asthma. Global strategy for asthma management and prevention. 2014. (http://www.ginasthma.org/)

25. Gluck JC. The change of asthma course during pregnancy. Clin Rev Allergy Immunol 2004;26:171-80. 